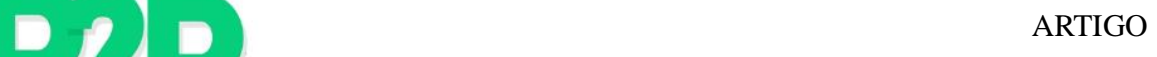

\title{
A CONSTRUÇÃO DO COMUM ATRAVÉS DA PRODUÇÃO PEER
}

\section{Janice Figueiredo}

Bacharel em Ciência da Computação (Unicamp), mestra em Comércio Internacional (Université de Poitiers, France) com cursos de pós-graduação na área de sustentabilidade (SOAS, University of London). Coordenadora de pesquisa da área de "Infraestruturas abertas para a vida coletiva" do projeto "FLOK Society" na Universidade Nacional de Pós-Graduação do Equador (IAEN), (novembro 2013 - junho 2014). Pesquisadora independente nas áreas de dinâmicas P2P, movimentos colaborativos, inteligência coletiva, moedas complementares, negócios sociais, desenvolvimento sustentável e redução da pobreza, com particular interesse na exploração, de modelos alternativos aos paradigmas econômicos convencionais baseados na centralização e na escassez.

\section{Resumo}

Nos atuais modos de funcionamento do mercado e do Estado, a sociedade civil não tem possibilidade de criar valor a partir de sua visão sobre o que é necessário para sua comunidade. Na lógica do mercado, bens e serviços são produzidos com o objetivo principal de obtenção de lucro e no Estado representativo os cidadãos não têm poder de decisão sobre as políticas públicas necessárias para suas cidades. Este artigo introduz a ideia do comum, que situa a noção de valor na criação colaborativa visando a resultados voltados para o coletivo. Em seguida, é apresentada a idéia de inteligência coletiva - aquela universalmente distribuída entre os seres humanos e que permite a criação de soluções inteligentes para problemas complexos; o documento sugere que o exercício dos valores do comum aprimora a inteligência coletiva. A partir das características da produção e governança peer, o artigo indica como cidades no mundo vêm sendo transformadas. Finalmente, a iniciativa Rio+ é apresentada como um modelo colaborativo que permite que a sociedade civil carioca proponha soluções para sua cidade.

Palavras-chave

P2P. Comum. Produção Peer. Governança peer. Inteligência coletiva. Colaboração.

\section{CONSTRUCTION OF COMMON THROUGH PEER PRODUCTION}

\begin{abstract}
Within the current working modes of the market and the State, civil society does not have the possibility to create value based on its own vision of what is needed for its communities. In the logic of the market, goods and services are produced with the ultimate goal of profit-making and, within the representative State, citizens do not take part in the decision-making processes that define the necessary public policies for their cities. This article presents the vision of the commons, that places the notion of wealthiness in what is created collaboratively and is aimed towards collective-oriented results. The document introduces the idea of the collective intelligence, which is universally distributed among human beings and which allows the creation of intelligent solutions to complex problems; the paper suggests that the exercise of the values of the commons enhances the collective intelligence. Through the characteristics of peer production and peer governance the article indicates how cities in the world are being transformed. Finally, the Rio+ initiative is presented as a collaborative model that allows civil society in Rio de Janeiro to create solutions for the city.
\end{abstract}

\section{Keywords}

P2P. Commons. Peer production. Peer governance. Collective intelligence. Collaboration. 


\section{INTRODUÇÃO}

Vivemos em um mundo onde a criação de valor se faz e é reconhecida dentro do contexto do mercado: uma pessoa cria valor enquanto trabalhador, indivíduo vinculado a uma corporação e a quem se remunera em troca daquilo que produz. O produto final - bem ou serviço - sua forma e seu tempo de produção são quase sempre definidos por instâncias hierárquicas corporativas que funcionam de forma vertical top-down: o trabalhador é um mero executor de decisões tomadas por poucos, situados no topo da pirâmide hierárquica corporativa.

Dentro dessa lógica, raramente - ou nunca - um indivíduo, enquanto cidadão, tem a possibilidade de criar valores de acordo com sua visão de mundo e suas necessidades. Em um artigo propondo orientações básicas para reformas sociais, Bauwens afirma que "em um sistema capitalista, a 'sociedade civil' não é diretamente produtiva dos bens e serviços necessários para a sobrevivência, a vida e a prosperidade" (BAUWENS, 2011).

Uma das características do modelo democrático ocidental é a de ser regido por um Estado democrático representativo: através de um sistema de referendo, os cidadãos de um Estado entregam nas mãos de governantes a responsabilidade pela elaboração das políticas públicas que nortearão suas vidas. Nesse modelo representativo, o cidadão tampouco tem a possibilidade de escolher, conforme seus próprios valores e sua visão de mundo, o que quer para a comunidade onde vive.

Nos últimos anos, cidadãos em várias partes do mundo vêm protestando contra o modelo econômico ditado pelo mercado e contra as estruturas dos governos representativos (HARDT \& NEGRI, 2012), através dos movimentos Occupy, iniciados em outubro de 2011. De um lado, o mercado preconiza os valores da competição, do acúmulo de riquezas, da maximização de lucros, em curto prazo, atuando com uma visão utilitária e mercantilista da natureza, dos animais e do próprio ser humano e estimulando comportamentos sociais não solidários: "o neoliberalismo exalta o individualismo, o consumismo e a propriedade privada, enquanto menospreza a generosidade e a solidariedade" (BOFF, 2011). De outro lado, existe a falha da instituição pública em servir adequadamente seus cidadãos: Mattei afirma que "o Estado não é mais a representação democrática de um agregado de indivíduos, mas um ator do mercado, entre tantos outros." (MATTEI, 2011). Várias pesquisas indicam que a atual democracia representativa passa por uma profunda crise de legitimidade: em 2013, a União Européia indicou que 68\% dos europeus não 
acreditam que suas vozes tenham valor na Europa ${ }^{1}$; uma pesquisa do Instituto Gallup aponta que, em 2009, somente $19 \%$ dos americanos acreditavam que o governo fazia o que é certo "quase sempre" ou "na maioria das vezes", enquanto $81 \%$ confiam no governo "algumas vezes" ou "nunca" ${ }^{2}$. Esses dados são uma forte indicação de que a sociedade civil não crê no Estado como o representante de seus interesses, disposto a escutá-la e capaz de atender às suas necessidades.

Os protestos brasileiros de junho de 2013 mostram o descontentamento profundo da população brasileira com ambos os atores: se inicialmente as manifestações populares surgiram em algumas cidades como um protesto contra o aumento nas tarifas de transporte público, rapidamente elas se proliferaram por todo o país como um protesto generalizado, englobando uma diversidade de temas: qualidade do transporte público, segurança, combate à corrupção, educação, moradia ${ }^{3}$.

De maneira geral, a civilização contemporânea sofre uma crise de valores e de um malestar difuso, consequente do descuido e do descaso. É cada vez maior o número de pessoas que não se reconhece nos valores do individualismo, da competição e do consumismo difundidos pelo mercado, e que não se sentem representadas pelo Estado. Em seu livro "Saber Cuidar", Leonardo Boff cita os sintomas da crise civilizacional derivados da falta do cuidado: pobreza, desemprego, exclusão de milhões (considerados como descartáveis ou zeros econômicos) dos processos de produção. (BOFF, 2011).

O mundo precisa de alternativas à lógica individualista do mercado e à centralização do Estado. Este artigo propõe que a sociedade civil é capaz de construir coletivamente suas comunidades através da produção peer $^{4}$ como uma alternativa a essa lógica.

\section{O Comum}

Na lógica do mercado, a criação artificial de escassez é necessária para que o mesmo garanta sua meta principal: a obtenção de lucro. Uma das formas utilizadas pelo mercado para produzir artificialmente escassez é através do estabelecimento do conceito de "propriedade privada" e de mecanismos para sua regulação. O direito autoral, por exemplo, garante a

\footnotetext{
${ }^{1}$ Debate sobre o futuro da Europa: Vice-Presidente Reding encontra-se com cidadãos em Coimbra <http://europa.eu/rapid/pressrelease_IP-13-129_pt.htm>

${ }^{2}$ Trust in Government <http://www.gallup.com/poll/5392/ trust-government.aspx>.

${ }^{3}$ Um mapeamento das palavras mais utilizadas nas mídias sociais, indicando as reinvindicações mais presentes nas manifestações. <http://codigoabiertocc.files.wordpress.com/ 2013/06/captura-de-pantalla-2013-06-22-a-las-02-23-19.png>.

${ }^{4} \mathrm{O}$ conceito de produção peer é explicado na página 32.
} 
"propriedade" do resultado de um pensamento a seu autor; a patente assegura o monopólio da exploração de uma invenção a seu criador; a licença regula a distribuição de software, e assim por diante. Uma vez estabelecida, a "propriedade privada" artificialmente criada pode, então, ser monetizada. O que era naturalmente abundante e ilimitado - o conhecimento contido em um livro ou em uma composição musical, o know-how para a reprodução de uma invenção, um software que poderia ser distribuído infinitamente ou modificado - passa a ser privilégio daqueles que podem ter acesso ao que foi criado. Nesses casos, "acesso" normalmente significa "poder pagar pelo seu uso". Essa lógica é excludente (quem não pode pagar, não tem acesso), gera comportamento individualista (os criadores são incitados a assegurar a propriedade intelectual de suas criações) e competitivo.

Quando a noção de "propriedade privada" é eliminada, é possível centrar-se na ideia do coletivo, do compartilhamento e da inclusão de todos. Cria-se, então, uma outra lógica: a do comum. A noção do comum encontra-se na Roma antiga: naquela época, um dos cinco tipos de propriedades existentes era o res communes, ou aquele pertencente a toda comunidade. Res communes refere-se ao ar, água e é o mais análogo ao que hoje se define como comum. ${ }^{5} \mathrm{O}$ site Onthecommons.org define o comum da seguinte maneira:

O comum é uma nova maneira de expressar uma antiga ideia - a de que certas riquezas pertencem a todos nós, e que esses recursos comunitários devem ser ativamente protegidos e administrados para o bem de todos. O comum é aquilo que herdamos e criamos coletivamente e que perdurará (assim esperamos) nas gerações vindouras. $\mathrm{O}$ comum consiste nos presentes da natureza, tais como ar, água, os oceanos, a vida e as terras selvagens, e "posses" compartilhadas, como internet, ondas de rádio utilizadas para transmissões e solos públicos. O comum também inclui nossas criações sociais compartilhadas: livrarias, parques, espaços públicos, assim como pesquisa científica, trabalhos criativos e conhecimento público que se acumulou ao longo dos séculos. (ON THE COMMONS, 2001) $)^{6}$.

O comum empodera ao proporcionar direitos e estimula o senso de responsabilidade ao exigir o cuidado pelo coletivo: todos têm igual direito a uma parcela do comum e igual responsabilidade por sua preservação e transferência para gerações futuras (MATTEI, 2013). A visão do comum é inclusiva e ninguém pode ser deixado de fora - pobre, vulnerável, deficiente, humano e não humano - todos, ainda que não se manifestem, devem ser considerados pelos agentes do comum (commoners).

\footnotetext{
${ }^{5}$ Res, em latim, significa coisa. A lei da Roma antiga reconhecia cinco categorias consideradas como propriedade impessoal: 1) res nullus, coisas que não pertencem a ninguém; 2) res communes, coisas pertencentes a todos, devido à sua natureza: oceanos, ar 3) res publicae, coisas que pertencem ao público por lei (parques, pontes,rios) 4) res universitatis $=$ coisas pertencentes a um grupo, tal como igreja, universidade, vilarejos. 5) res divini juris, coisas que não podem pertencer a humanos, por terem um status divino. (Millun, 2007)

${ }^{6}$ About the commons <http://onthecommons.org/about-commons>.
} 
O comum é holístico. Considera o ser humano como interdependente e é baseado na cooperação. "No comum, as pessoas podem viver da forma como sempre foram: seres sociais que, juntos, criam suas condições de vida" (MERETZ, 2013).

O comum resgata valores humanos. Na introdução do livro “A Riqueza do Comum” (The Wealth of the Commons), David Bollier e Silke Helfrich indicam:

\begin{abstract}
No exato momento em que deixamos de falar de modelos de negócios, de eficiência e de lucro como prioridades, deixamos de nos ver como Homo economicus e como objetos a serem manipulados por planilhas eletrônicas. Começamos a nos ver como "commoners" em relação com outras pessoas, com uma história e futuro compartilhados. Começamos a criar uma cultura de cuidado e corresponsabilidade para com nossos recursos comuns, ao mesmo tempo em que defendemos nossa subsistência. (BOLLIER; HELFRICH, 2013)
\end{abstract}

Ao olharmos o mundo sob a ótica do comum, percebemos que há mais criatividade, mais diversidade, mais oportunidades para aprendizado e uma considerável melhoria na qualidade de vida. Uma cultura do comum possibilita a invenção de novas formas - inclusivas e holísticas - de funcionamento de uma sociedade voltada para todos. O comum é criado por querer-se o cuidado à comunidade: manter sua subsistência, assegurar a integração de todos, sua distribuição equitativa e seu uso responsável por todos.

A lógica do comum se orienta a valores distintos daqueles preconizados pelo mercado. $\mathrm{O}$ quadro 1 compara os valores de ambos.

Quadro 1: Valores o Mercado X Valores do Comum ${ }^{7}$

\begin{tabular}{|l|l|}
\hline \multicolumn{1}{|c|}{ Mercado } & \multicolumn{1}{c|}{ Comum } \\
\hline Eu & Nós \\
\hline O que posso vender? Valor de troca & O que necessitamos? Valor de uso \\
\hline Escassez & Abundância \\
\hline Homo economicus & Homo cooperans \\
\hline Concentração & Diversidade \\
\hline Dependência & Interdependência \\
\hline Fragmentação & Integração \\
\hline Exclusão e participação das pessoas & Inclusão e emancipação das pessoas \\
\hline Decisões hierárquicas & Decisões horizontais \\
\hline Comando e controle & $\begin{array}{l}\text { Consenso, cooperação voluntária, auto- } \\
\text { organização }\end{array}$ \\
\hline Clientes & Indivíduos pertencentes à comunidade \\
\hline Eficiência & Diversidade de expressão \\
\hline
\end{tabular}

\footnotetext{
${ }^{7}$ Adaptado de 1) The Commons: Year One of the Global Commons Movement (Silke Helfrich) e 2) The Economy of Wastefulness: the Biology of the Commons. (Andreas Weber)
} 


\begin{tabular}{|l|l|}
\hline Consumo dos recursos naturais & Conservação, Reprodução e Multiplicação \\
\hline Sustentabilidade = vitória & $\begin{array}{l}\text { Sustentabilidade = relacionamento e } \\
\text { engajamento }\end{array}$ \\
\hline Vencedores monopolizam os recursos & $\begin{array}{l}\text { Vencedores estão profundamente } \\
\text { conectados às necessidades da comunidade }\end{array}$ \\
\hline Local X global & Local e global holisticamente integrados \\
\hline Egos em ambientes hostis & Constante reinvenção da comunidade \\
\hline
\end{tabular}

\section{Inteligência Coletiva}

O século XXI será aquele dos problemas complexos globais. A sociedade global terá que encontrar meios de proporcionar uma melhor qualidade de vida ao 1/3 da população mundial que ainda vive na pobreza ${ }^{8}$ sem aumentar a pegada ecológica global - atualmente em $1.5^{9}$ - que já é maior do que a capacidade do planeta de repor os recursos naturais consumidos; para minimizar as catástrofes consequentes do aquecimento global, terá que encontrar e implementar alternativas à forte dependência do petróleo no transporte, na indústria e na energia - setores que mais emitem $\mathrm{CO}_{2}$ (o maior responsável pelo aquecimento global). As projeções das consequências do aquecimento global incluem degradação dos recursos hídricos, insegurança alimentar, aumento da pobreza e miséria, perdas da biodiversidade, migração climática, desastres ecológicos causados por secas, inundações e tsunamis. O crescimento populacional implica uma maior necessidade de consumo de matérias-primas não renováveis e maior geração de resíduos. As fragilidades sistêmicas do atual sistema financeiro e a incapacidade do mercado e do Estado de encontrar soluções adequadas podem dar início a um colapso do sistema econômico mundial.

Para resolver problemas complexos à escala global serão necessárias reflexões profundas, que envolvam conhecimentos multidisciplinares capazes de gerar soluções criativas, inclusivas e duradouras. A inteligência coletiva será, provavelmente, a chave para a criação de soluções altamente complexas, inovadoras e que conciliem diversidades geográficas, políticas, religiosas e culturais.

O princípio básico da inteligência coletiva é que, juntos, somos capazes de agir de forma mais inteligente do que individualmente. O resultado criado através do coletivo é maior do que

\footnotetext{
${ }^{8}$ Em 2010, de acordo com o índice multidimensional da pobreza (MIP) definido pela UNDP. São considerados pobres multidimensionais aqueles com pelo menos $33 \%$ de indicadores refletindo alta privação da saúde, da educação e da qualidade de vida.

${ }^{9}$ Global Footprint Network <http://www.footprintnetwork. org/pt/index.php/GFN/page/world_footprint/>.
} 
aquele criado individualmente, pois permite que idéias sejam enxergadas e analisadas a partir de distintos pontos de vista.

O filósofo tunisiano Pierre Lévy propõe a seguinte definição de Inteligência Coletiva: “É uma forma de inteligência universalmente distribuída, constantemente aprimorada, coordenada em tempo real e resultando na mobilização efetiva de aptidões” (LÉVY, 2004).

É possível observar as seguintes implicações dessa definição ${ }^{10}$ :

a) Inteligência universalmente distribuída: todo o conhecimento se encontra na humanidade. Ninguém sabe tudo e toda pessoa sabe algo;

b) Constantemente aprimorada: cada indivíduo possui uma riqueza inerente e única, com potencial de agregar valor à inteligência coletiva. Portanto, a fonte agregadora de valor está centrada em cada ser humano. Sendo a inteligência coletiva resultante da contribuição das riquezas individuais de cada membro de um coletivo, a aprimoração da inteligência coletiva será maior, quanto maior for a quantidade de pessoas contribuidoras de valores em um coletivo;

c) Coordenada em tempo real: esta é uma referência ao ciberespaço, o meio pelo qual a inteligência coletiva atinge uma escala global. Pessoas conectadas à internet formam parte do coletivo global e suas riquezas individuais estão, assim, disponíveis à inteligência coletiva global. Dessa forma, quanto mais pessoas estiverem conectadas à internet, maior será a disponibilidade de riquezas individuais para a inteligência coletiva global;

d) Resultando na mobilização efetiva de aptidões: a inteligência coletiva não é um conceito teórico ou filosófico, ela pode significar uma nova forma de organização social efetiva e eficaz, baseada em aptidões e conhecimentos que podem ser exercidos e aplicados de forma concreta.

Os valores do comum - cooperação, inclusão, relações horizontais, acesso aberto, copyleft, valorização da diversidade e do exercício da autonomia, reconhecimento da interdependência, estímulo à emancipação - proporcionam a aprimoração da inteligência coletiva, pois estes favorecem a contribuição do indivíduo ao coletivo.

A internet é o veículo que permite que qualquer pessoa se conecte a outra em qualquer parte do planeta. A atribuição de conectividade à internet a todo indivíduo do planeta permitirá o nascimento de uma inteligência coletiva global.

A inteligência coletiva global seria a forma suprema de inteligência, capaz de inventar coisas que não somos capazes de imaginar como indivíduos ou grupos regionais. A inteligência

\footnotetext{
${ }^{10}$ Análise adaptada de <http://unblogdesblogs. wordpress.com/2013/07/02/daristote-au-web-de-demain-lintelligencecollective-selon-pierre-levy/>.
} 
coletiva global pode ser a chave para a resolução do aquecimento global e suas consequências, do colapso financeiro, das guerras, dos conflitos religiosos e políticos.

O século XXI pode ser aquele das profundas reflexões transcontinentais, da co-criação de grandes inovações resultantes da forte interatividade global, das mudanças radicais dos valores sociais, da criação de valores coletivos globais, do resgate dos valores humanos mais nobres: generosidade, autenticidade e cuidado.

Para onde poderia nos levar uma sociedade que funcionasse dessa maneira?

Em seu artigo "Retorno ao Paraíso? Promessas e Perigos no Caminho para a Inteligência Global Onipotente", Heylighen argumenta que, coletivamente, estamos nos aproximando de uma inteligência supra-humana com capacidades próximas aos atributos divinos:

\begin{abstract}
"Essa 'mente global' servirá para abordar todos os desafios confrontados pelo 'superorganismo global'. Suas capacidades serão estendidas tão além de nossas atuais que serão melhor compreendidas como uma versão pragmática dos atributos divinos: onisciência (capacidade de conhecer tudo para resolver problemas), onipresença (disponibilidade a qualquer lugar, a qualquer momento), onipotência (capacidade de fornecer qualquer produto ou serviço a um custo irrisório) e onibenevolência (desejo da maior felicidade para o maior número. (...) O produto resultante da solução de todos os problemas individuais e sociais podem ser vistos como um retorno ao 'Jardim do Éden', o estado idílico da abundância e paz que supostamente existiu antes da civilização. Nessa sociedade utópica, indivíduos seriam apoiados e desafiados pela mente global para desenvolver ao máximo suas atitudes, e para criar novos conhecimentos de forma contínua". (HEYLIGHEN, 2013).
\end{abstract}

\title{
Produção e Governança Peer
}

Definiremos os termos "Peer-to-Peer", "Produção Peer" e "Governança Peer", apresentando suas lógicas e características.

Peer-to-Peer (par-a-par, pessoa-a-pessoa ou P2P) é uma dinâmica relacional característica de redes distribuídas e baseadas na contribuição, onde cada participante é equipotente e tem autonomia para se relacionar diretamente com qualquer outro participante da rede ${ }^{11}$.

Uma topologia de rede distribuída proporciona as seguintes características relacionais:

a) Não hierarquia: a inexistência de um centro (topologia centralizada) ou de múltiplos centros (topologia descentralizada) permite que as relações sejam horizontais;

b) Equipotência: a horizontalidade implica em que todos participantes tenham, inicialmente, o mesmo poder de atuação. Os reconhecimentos diferenciados que se fazem ao longo da

\footnotetext{
${ }^{11}$ Adaptada da definição da P2P Foundation <www.p2pfoundation.net〉.
} 
dinâmica serão determinados pelo envolvimento de cada um na execução de tarefas, conhecimentos sobre o tema e atitudes em relação ao grupo (e não resultantes de uma posição de poder pré-estabelecida);

c) Autonomia: cada participante se relaciona diretamente com qualquer outro, quando e se quiser, de acordo com sua vontade, afinidade, disponibilidade, sem necessidade de pedir permissão a ninguém.

Produção Peer (ou Produção P2P) é um processo P2P voltado para a criação do comum.

A lógica da produção peer é baseada na criação e preservação do comum, na mutualização de conhecimentos ou coisas físicas e na satisfação dos interesses do coletivo através da cooperação e do compartilhamento. A produção peer entende que múltiplos indivíduosfragmentos, ao se unirem, têm o potencial de construir um coletivo-unificado benéfico para todos. O motto "dê um tijolo, ganhe uma casa" sintetiza bem essa lógica. O resultante da produção peer tem código aberto, é copyleft e sua licença é coletiva.

O modo de produção peer inclui as seguintes características:

a) Distribuição de tarefas: não existem papéis ou funções a serem desempenhados e sim tarefas específicas a serem executadas;

b) Anti-credencialismo: não há necessidade de haver diplomas, credenciais ou, em certos casos, até mesmo experiência para se realizar determinadas tarefas;

c) Anti-rivalidade: entende-se que o compartilhamento do comum aumenta seu valor. Por isso, não faz sentido a lógica da competição e da manutenção de segredos;

d) Modularidade: tarefas, produtos e serviços são organizados em módulos que se encaixam em outros módulos, como em um lego;

e) Granularidade: módulos podem ser quebrados em sub-módulos, para que tarefas complexas se tornem mais simples, o que facilita sua realização por um maior número de pessoas;

f) Holoptismo: a informação do projeto é transparente e seu "código fonte" está sempre disponível;

g) Prod-uso (do inglês produsage): não existe uma separação estrita entre produção e consumo. Usuários finais podem ser os produtores das soluções; 
h) Estigmergia: mecanismo de coordenação espontânea entre agentes e ações que permite que as necessidades de um sistema sejam comunicadas e cheguem àqueles capazes de contribuir para sua realização;

i) Validação da comunidade: o controle de qualidade se estabelece pela comunidade de forma post-hoc;

j) Negociação coordenada: conflitos são resolvidos através de um diálogo contínuo e mediado, e não através de decisões centralizadas e hierárquicas.

A título de exemplo, faremos o exercício de ver o trabalho de um cozinheiro dentro da lógica da produção peer: Não haveria o entendimento de "cozinheiro" como uma função ou cargo. Haveria tarefas específicas a serem cumpridas para a produção do resultado almejado (comida): comprar legumes, cortar legumes, cozinhar legumes, etc. Essas tarefas seriam modularizadas e granuladas de acordo com sua complexidade e capacidade/ disponibilidade dos envolvidos em executá-las.

Poderíamos, por exemplo, granular o módulo "cortar cebola" nas seguintes tarefas:
a) Abrir a gaveta
b) Pegar a faca
c) Passar a faca para pessoa $X$
d) Fazer corte 1
e) Fazer corte 2

\section{(...)}

n) Fazer corte $\mathrm{N}$

Qualquer pessoa capaz de realizar alguma dessas tarefas poderia, de forma autônoma, executá-la. A forma de execução ("código fonte") de cada uma dessas tarefas estaria disponível para todos. Em caso de conflitos quanto à forma de execução de algum desses módulos ou tarefas (por exemplo, divergência de opinião quanto à forma de executar a tarefa "fazer corte"), o conflito seria levado para dentro do grupo, discutido e uma solução seria encontrada à partir da interação entre seus membros. Uma pessoa poderia executar uma ou múltiplas tarefas, de acordo com sua vontade e disponibilidade. Ou poderia nada fazer. O produto final (comida) estaria disponível para toda a comunidade (incluindo aqueles que não participaram da execução das tarefas); qualquer pessoa poderia se apropriar do "código fonte para a realização da comida", podendo reutilizá-lo e modificá-lo. 
Se para cortar uma cebola esse nível de granularidade não faz sentido, em projetos altamente complexos a modularização/granulação torna possível sua realização.

Através da lógica da produção peer, centenas de voluntários (engenheiros, donas de casa, crianças, artistas, etc), localizados em 12 países distintos, foram capazes de construir, em apenas três meses e em micro-fábricas, um carro esportivo "open source". Graças a seu desenho modular, cada módulo pôde ser construído de forma independente, em diferentes partes do mundo, e em seguida ser encaixado aos demais. Essa forma de produção peer contrasta com o modelo de produção industrial capitalista, que funciona de forma linear e segue a lógica do comando/controle, onde se necessita permissão para passar à etapa seguinte de construção.

O automóvel é extremamente veloz, alcançando $97 \mathrm{~km} / \mathrm{h}$ em apenas 5 segundos; é econômico (faz 50km/litro na estrada e $44 \mathrm{~km} /$ litro na cidade, marcas que superam as de qualquer carro construído em fábricas). A iniciativa leva o nome de Wikispeed ${ }^{12}$.

Governança Peer (ou Governança P2P) é a forma de administração da produção peer, caracterizada pela heterarquia.

Principais características:

a) Heterarquia: estratégia organizacional onde o poder é compartilhado por todos de forma igual;

b) A heterarquia tem natureza bottom-up;

c) A heterarquia é altamente inclusiva;

d) Forking: a natureza copyleft e open-source da produção peer permite que um grupo se dissocie do projeto e continue sua construção de forma independente.

Segundo Timothy Wilken,

A heterarquia é ideal para a comunicação e discussão, pois permite o compartilhamento de responsabilidades e autoridade. As tarefas atribuídas, consequências de discussões abertas, produzem relações de trabalho mais cooperativas. Quando participantes sentemse valorizados, surgem a abertura e a integridade. As pessoas voluntariamente se oferecem para mais tarefas. Há menos conflito, os resultados são mais eficientes, há uma maior produtividade e qualidade do dia-a-dia laboral. A heterarquia cria a sensação de pertencimento comunitário. Há uma identificação com o sistema. Heterarquia é altamente inclusiva: todos se sentem parte do sistema e seus participantes tendem a protegê-lo. O foco integral conduz a decisões coletivas e responsabilidades coletivas. (WILKEN, 2002).

\footnotetext{
${ }^{12}$ Wikispeed <http://wikispeed.org/>; <http://p2pfoundation.net/WikiSpeed>
} 
Se, por um lado a tomada de decisões é mais lenta na heterarquia (pois é necessário um tempo maior para se chegar a um consenso), a implementação de soluções é muito mais rápida, pois o processo de implementação já terá sido discutido durante a fase de tomada de decisões. Isso não somente elimina conflito: encoraja os membros a se sentirem responsáveis pelo sucesso da implementação das soluções.

O potencial da governança peer pode ser plenamente apreciado na iniciativa "Burning Man”. Guiados por dez princípios básicos ${ }^{13}$, entre os quais a inclusão (todos são bem-vindos a fazer parte da comunidade), a descomodificação (não há comercialização de qualquer tipo), a autossuficiência, a auto-expressão, o esforço da comunidade, a responsabilidade cívica, a sustentabilidade e a participação, há quase 30 anos pessoas de todas as partes do mundo co-criam, no isolado deserto de Nevada, um bem comum: a cidade-temporária autossustentável "Black Rock City", onde todos os anos acontece um festival de arte e cultura. Toda a infraestrutura típica de uma cidade é criada coletivamente a partir do zero: provisão de eletricidade, instalação de sistemas de iluminação, sistemas de água potável, instalações sanitárias, coleta de resíduos e sistema de reciclagem, serviços de atendimento à população (como médicos e bombeiros), estradas, aeroporto, sistemas de comunicação (jornal e rádio), entre outros. ${ }^{14}$

Ao final do festival, tudo desaparece: nenhuma instalação, objeto ou traço é deixado no deserto, que volta a seu estado original. No ano seguinte, a construção se inicia novamente do zero.

No contexto da criação do comum através da produção peer, poderíamos enxergar essa "evaporação" da cidade como um reconhecimento da comunidade de que o valor do comum reside na fonte capaz de produzi-lo: a comunidade, seus conhecimentos e sua capacidade de realizar de forma coletiva. Em outras palavras, na inteligência coletiva da comunidade.

\section{Cidades Colaborativas}

O exemplo do Burning Man mostra que a sociedade civil, quando livre e autônoma, é capaz de se auto-organizar, assumir responsabilidades e consegue prover os bens e serviços necessários para sua sobrevivência.

\footnotetext{
${ }^{13}$ Ten Principles of Burning Man<http://www.burningman. com/whatisburningman/about_burningman/principles.html\#.UmUQhlBwofo>.

${ }^{14} \mathrm{O}$ festival reuniu 68.000 pessoas em agosto de 2013, o que representaria a segunda maior cidade de Nevada.
} 
Em várias partes do mundo encontramos iniciativas, onde a sociedade civil constrói soluções para a cidade.

Na Inglaterra, a iniciativa FixMyStreet permite que qualquer cidadão reporte, via internet, problemas encontrados nas ruas e estradas, tais como a existência de buracos nas ruas ou de lâmpadas quebradas, às administrações responsáveis. A informação permanece disponível para que qualquer pessoa veja todos os problemas reportados. O modelo, iniciado na Inglaterra, espalhou-se pelo mundo e, na data de hoje, outros 14 países implementaram a iniciativa ${ }^{15}$.

Em 2006, a cidade francesa de Brest convidou todos os moradores, associações, jornais de bairros, artistas, jornalistas e cidadãos, em geral, a escreverem juntos a história da cidade. Nasceu, assim, a plataforma wiki-brest.net, uma enciclopédia colaborativa viva, alimentada de formas variadas: em forma de artigos, canções, depoimentos, fotos, etc. A iniciativa permite que os cidadãos resgatem o passado, compartilhem o presente e desenhem o futuro imaginado para a cidade.

A cidade de Linz, na Áustria, se propõe a construir um grande ecossistema dos comuns e transformar a política, governança e cultura da cidade através do uso da internet. A iniciativa, chamada de "Open Commons Region Linz", visa criar um ecossistema baseado no software livre, em licenças Creative Commons, em plataformas de dados abertos, em recursos educacionais abertos e cultura e ciência abertas ${ }^{16}$.

Em 2012, a Islândia produziu a primeira constituição crowdsourced do mundo, baseandose em sugestões enviadas diretamente de seus cidadãos, via facebook e twitter.

Entre as inúmeras vantagens da governança peer nas cidades, destacamos:

a) O resgate do senso de cidadania, já que qualquer pessoa pode contribuir, de forma horizontal e sem necessidade de solicitar permissão;

b) As soluções produzidas são adicionadas ao pool dos comuns e toda a sociedade civil é beneficiada;

c) A valorização das ideias, da criatividade e da imaginação dos cidadãos;

d) Fortalecem-se os laços comunitários, estimula-se o diálogo e o aprendizado coletivos;

e) A tomada de decisões vai muito além da participação: permite que os cidadãos se apropriem de seus futuros políticos.

\footnotetext{
${ }^{15}$ Fixmystreet <http://en.wikipedia.org/wiki/FixMyStreet.>

${ }^{16}$ BOLLIER, 2011.
} 
O envolvimento direto dos cidadãos na construção das cidades favoreceria 0 desenvolvimento das mesmas. Essa dinâmica de produção peer cívica está alinhada com a definição de desenvolvimento de Amartya Sen, que o define como "um processo de expansão das liberdades individuais, onde pessoas têm a possibilidade de exercer aquilo que gostam". (SEN, 1999, p. 3).

\section{Rio+: uma iniciativa carioca de produção peer para construção do comum}

Em abril de 2013 foi criada na cidade do Rio de Janeiro a plataforma online colaborativa "Rio+""17, que permite que qualquer cidadão apresente ideias de melhorias para a cidade e visa a implementar as melhores sugestões.

A iniciativa dividiu-se em quatro etapas principais: durante seis meses a plataforma manteve aberta a primeira fase, a da "Convocação Criativa", quando qualquer pessoa com acesso à internet pôde ingressar quantas ideias quisesse. Em seis meses, a plataforma capturou quase 1700 ideias, divididas em 12 temáticas ${ }^{18}$ e originadas por mais de 700 pessoas. As propostas permanecem visíveis no site e, através de uma interface com a mídia social facebook, é possível que qualquer pessoa (ainda que não tenha ingressado nenhuma ideia) "curta”, dialogue com outros interessados em uma mesma proposta e contribua com sugestões de como aprimorar ainda mais cada ideia. Nessa primeira fase, a totalidade das propostas apresentou mais de 31.000 "curtidas".

Em seguida, as sugestões enviadas pelos cidadãos foram analisadas por especialistas - a equipe da Rio+ e uma universidade parceira no Rio de Janeiro" ${ }^{19}$ - na segunda fase, a do "Estudo de Viabilidade". Nessa fase, que teve início em outubro de 2013, foram selecionadas as duas melhores propostas dentro de cada uma das 12 temáticas, de acordo com os seguintes critérios: viabilidade legal e técnica, impacto ambiental, custo ${ }^{20}$, replicabilidade, inovação. Qualquer estudante da universidade parceira pôde fazer parte do estudo de viabilidade. É nesta etapa,

\footnotetext{
${ }^{17}$ RioMais <http://riomais.benfeitoria.com/>

${ }^{18}$ Cada ideia ingressada corresponde a uma das 12 categorias disponíveis: 1.Cidadania; 2.Cultura e Artes; 3.Comunidades; 4.Educação; 5. Esporte e Lazer; 6.Inclusão; 7.Inovação; 8. Intervenção Urbana; 9. Mobilidade; 10.Praia, Praça e Parque; 11. Saúde e Bem-Estar; 12.Sustentabilidade

${ }^{19}$ A Fundação Getúlio Vargas (FGV), através da Clínica LAJUNN (Laboratório de Assessoria Jurídica a Novos Negócios) do Núcleo de Práticas Jurídicas (NPJ), FGV DIREITO RIO, é parceira da iniciativa Rio+ para a fase de estudo de viabilidade dos projetos. Qualquer estudante de alguns dos Campi da FGV-Rio poderá participar do estudo de viabilidade.

${ }^{20} \mathrm{O}$ custo de cada projeto não deve ultrapassar $\mathrm{R} \$ 100 \mathrm{mil}$.
} 
também, que se buscaram os parceiros em potencial, capazes de viabilizar a implementação das ideias.

Na terceira fase, a da "Votação Popular", realizada em abril de 2014, o conjunto de propostas consideradas viáveis voltou ao público para votação: as mais votadas em cada uma das temáticas serão implementadas pela Prefeitura do Rio $^{21}$. Vale observar que, nesta etapa, além da possibilidade de votação via internet, o público pôde manifestar suas preferências offline, em pontos distribuídos pela cidade, permitindo a inclusão no processo de votação daqueles que não têm acesso à internet.

A seguinte etapa, a da "Realização", consiste na implementação de 13 projetos (12 pela Prefeitura do Rio e um por uma empresa da iniciativa privada), sob a forma de protótipo-teste, com possibilidade de tornar-se política pública para toda a cidade ${ }^{22}$.

\section{Aspectos da dinâmica P2P e do Comum na Iniciativa Rio+}

Reconhecemos alguns aspectos da dinâmica P2P na iniciativa Rio+: ao oferecer à sociedade civil a possibilidade de criar ideias para a cidade e de interagir com outros cidadãos sobre qualquer ideia, estimula-se a inclusão. A participação dá-se de forma horizontal e autônoma (não há necessidade de solicitar-se autorização a ninguém para a inserção de uma proposta ou de um comentário e qualquer um é livre para entrar a informação - ideia ou sugestão para uma ideia criada por outro - se e quando quiser). Toda proposta é, inicialmente, tratada de forma igual, indicando que os participantes são equipotentes. O acesso é aberto a qualquer um (basta ter conectividade à internet) e é transparente - todas as propostas, comentários e "curtidas" ficam visíveis e disponíveis para todos. Há, também, transparência na dinâmica do processo - todas as etapas e seus envolvidos são claramente definidos desde o princípio.

Essa dinâmica estimula a cooperação e o compartilhamento (a integração com o facebook e de seus módulos "curtir" e "comentar" facilitam a integração inter-comunitária), a geração de abundância (muitas ideias são criadas; ainda que não sejam implementadas, tornam-se fontes de inspiração para novas propostas), estimula a participação cidadã e valoriza a diversidade.

\footnotetext{
${ }^{21}$ A Prefeitura do Rio se compromete a implementar os projetos mais votados em cada uma das 12 categorias. Além disso, uma empresa da iniciativa privada se compromete a implementar o segundo projeto mais votado na categoria "Inovação", totalizando em 13 o número de projetos previstos para realização.

${ }^{22}$ Os impactos dos protótipos-testes serão mensurados pela FGV-Rio
} 
A fase "estudo de viabilidade", por ser fechada a um pequeno grupo com poder de decisão, não pode ser caracterizada como sendo uma dinâmica P2P.

$\mathrm{Na}$ fase 3 encontramos os mesmos elementos identificados na Fase 1, que são potencializados pela possibilidade de que pessoas votem de forma offline nos projetos préselecionados.

Um resumo dos aspectos $\mathrm{P} 2 \mathrm{P}$ na iniciativa Rio+ pode ser visto no quadro 2:

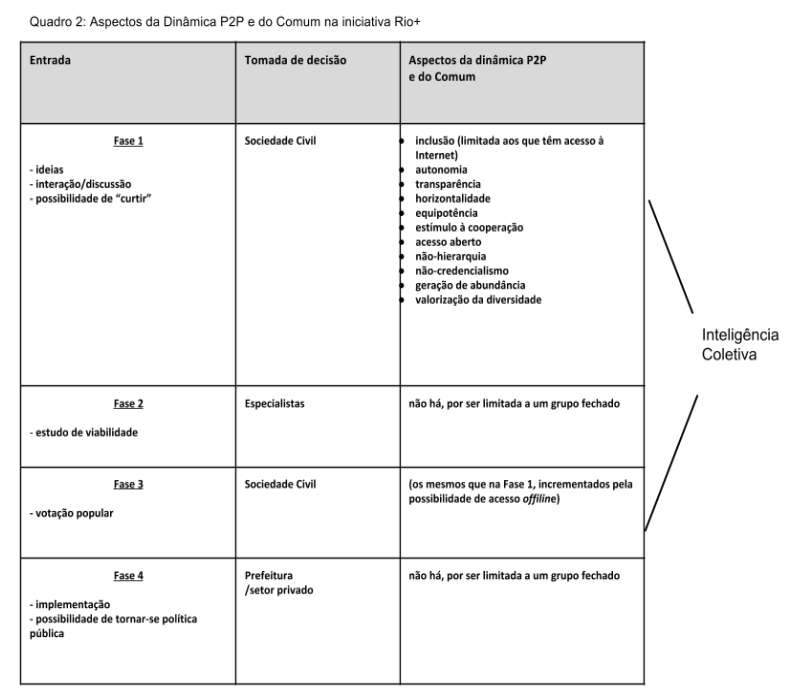

\section{CONSIDERAÇÕES FINAIS}

Quando aos cidadãos é dada a possibilidade da elaboração de soluções para suas comunidades e cidades, cria-se uma dinâmica contínua de geração de conhecimento. Este está sempre se aprimorando, já que o conhecimento coletivo permanece disponível para a comunidade e tem a possibilidade de se refinar, de se transformar, de amadurecer e de se multiplicar através das interações livres feitas entre os participantes de uma comunidade. Essa dinâmica de geração da abundância do conhecimento é uma nova forma de criação de valor feita pela sociedade civil, inexistente dentro do contexto tradicional do mercado e do Estado representativo.

Um mundo cada vez mais conectado pela internet amplia o potencial de criação de conhecimento, uma vez que agrega mais pessoas ao universo virtual. Ou seja, possibilita a criação de mais conhecimento (contido em cada novo indivíduo conectado) e de mais interações (que, por sua vez, têm o potencial de aprimorar conhecimentos). Portanto, dar acesso à internet a 
todo cidadão é contribuir com a criação de uma riqueza extraordinária, a de um patrimônio coletivo universal, o conhecimento global.

Quanto mais inclusivas, horizontais, equipotentes e abertas forem as relações entre as pessoas conectadas, maior e melhor será o conhecimento gerado: pessoas mais livres e autônomas são mais criativas e inovadoras. O exercício dessas relações permite o resgate de valores humanos mais nobres: o compartilhamento, a cooperação, o cuidado com a comunidade.

O que nossa civilização precisa é superar a ditadura do modo-de-ser-trabalho-produçãodominação. Ela nos mantém reféns de uma lógica que hoje se mostra destrutiva da Terra e de seus recursos, das relações entre os povos, das interações entre capital e trabalho, da espiritualidade e de nosso sentido de pertença a um destino comum. Libertados dos trabalhos estafantes e desumanizadores, agora feitos pelas máquinas automáticas, recuperaríamos o trabalho em seu sentido antropológico originário, como plasmação da natureza e como atividade criativa, trabalho capaz de realizar o ser humano e de construir sentidos cada vez mais integradores com a dinâmica da natureza e do universo $^{23}$ (BOFF, 2011)

Empoderar os cidadãos significa ressignificar a sociedade civil. É permitir sua emancipação dos valores do velho mundo - individualismo, competição, exclusão, escassez - e permitir a construção de um novo mundo baseado nos valores do coletivo, da cooperação, da inclusão e da abundância.

23 “Saber Cuidar", Leonardo Boff, p. 102. 


\section{REFERÊNCIAS}

ALTMAN, David. Bringing direct democracy back in: toward a three-dimensional measure of democracy. Democratization, Londres, v. 20, n. 4, p.615-641, abr. 2012. Disponível em: <http://dx.doi.org/10.1080/13510347.2012.659020>. Acesso em: 18 jul. 2014.

\section{BAUWENS, Michel. The basic orientation of P2P theory towards societal reform:} transforming civil society, the private and the state. 2011. Disponível em:

$<$ http://blog.p2pfoundation.net/the-basic-orientation-of-p2p-theory-towards-societal-reformtransforming-civil-society-the-private-and-the-state/2011/07/12>. Acesso em: 18 jul. 2014.

BOLLIER, David. The city of linz pioneers a regional information commons. 2011. E-book. Disponível em: <http://bollier.org/city-linz-pioneers-regional-information-commons>. Acesso em: 21 jul. 2014.

BOLLIER, David; HELFRICH, Silke. Introduction: the commons as a transformative vision. 2013. Disponível em: <http://wealthofthecommons.org/essay/introduction-commonstransformative-vision>. Acesso em: 21 jul. 2014.

D’ARISTOTE au web de demain: i'intelligence collective selon Pierre Lévy. 2013. Disponível em: <http://unblogdesblogs.wordpress.com/2013/07/02/daristote-au-web-de-demainlintelligence-collective-selon-pierre-levy/>. Acesso em: 21 jul. 2014.

Fix my Street. Disponível em: <http://www.fixmystreet.com/>. Acesso em: 21 jul. 2014.

FUNDAÇÃO GETÚLIO VARGAS (Rio de Janeiro). Últimos dias para o envio de Ideias para o Rio+. FGV Direito Rio. Rio de Janeiro. 14 out. 2013. Disponível em:

<http://direitorio.fgv.br/ultimos_dias_rio>. Acesso em: 21 jul. 2014.

HARDT, Michael; NEGRI, Antonio. Declaration. 2012. E-book. Disponível em:

<http://www.amazon.com.br/Declaration-Michael-Hardt-ebook/dp/B00816QAFY>. Acesso em: 21 jul. 2014.

HELFRICH, Silke. The Commons: year one of the global commons movement. 2011. Disponível em: <http://commonsblog.wordpress.com/2011/01/29/the-commons-year-one-of-theglobal-commons-movement/>. Acesso em: 21 jul. 2014.

HEYLIGHEN, Francis. Return to Eden? promises and perils on the road to a global. 2013. Disponível em: <http://pespmc1.vub.ac.be/Papers/BrinkofSingularity.pdf>. Acesso em: 21 jul. 2014.

Human Devolepment Reports. Disponível em: 〈http://hdr.undp.org/en/statistics/mpi/>. Acesso em: 21 jul. 2014. 
LÉVY, Pierre. L'intelligence collective: pour une anthropologie du cyberespace. Paris: La Découverte, 2004. 252 p. (Essais n.27)

MATTEI, Ugo. First thoughts for a phenomenology of the commons. 2013. Disponível em: $<$ http://wealthofthecommons.org/essay/first-thoughts-phenomenology-commons >. Acesso em: 21 jul. 2014.

MATTEI, Ugo. L'Etat, le marché et quelques questions préliminaires à propos du commun. 2011. Disponível em:

<http://works.bepress.com/cgi/viewcontent.cgi?article=1040\&context=ugo_mattei >. Acesso em: 21 jul. 2014

MERETZ, Stefan. The structural communality of the commons. 2013. Disponível em: <http://wealthofthecommons.org/essay/structural-communality-commons>. Acesso em: 21 jul. 2014.

MILUN, Kathryn. Wrapping our legal mnds around the global commons: res nullius, res communis, and res divini juris, On the Commons. 2007. Disponível em:

$<$ http://onthecommons.org/wrapping-our-legal-minds-around-global-commons-res-nullius-rescommunis-and-res-divini-juris>. Acesso em: 21 jul. 2014.

Open Commons. Disponível em: <http://opencommons.public1.linz.at/>. Acesso em 21 jul. 2014.

P2P Fundation. Disponível em: <http://p2pfoundation.net>. Acesso em 21 jul. 2014.

Red Pepper. Disponível em: <http://www.redpepper.org.uk/the-coming-of-the-commons/>. Acesso em: 21 jul. 2014.

Rio+. Disponível em: <http://riomais.benfeitoria.com/>. Acesso em: 21 jul. 2014.

Rio+. Disponível em: 〈https://www.facebook.com/riomais.vc>. Acesso em: 21 jul. 2014.

SEN, Amartya. Development as Freedom. Oxford: Oxford University Press, 1999.

TURNER, Fred. Burning man at google: a cultural infrastructure for new media production. 2009. Disponível em: <http://fredturner.stanford.edu/wp-content/uploads/turner-nms-burningman.pdf $>$. Acesso em: 21 jul. 2014.

WEBER, Andreas. The economy of wastefulness: the biology of the commons. 2013. Disponível em: <http://wealthofthecommons.org/essay/economy-wastefulness-biologycommons>. Acesso em: 21 jul. 2014. 
Wiki Brest. Disponível em: <http://wiki-brest.net/>. Acesso em: 21 jul. 2014.

WILKEN, Timothy. Ortegrity bridge to a synergic future. 2002. Disponível em: <http://www.synearth.net/Restricted-Confidential/OT.pdf>. Acesso em 21 jul. 2014. 